\title{
PLATONIC DIALOGUE AND GADAMERIAN HERMENEUTICS
}

\author{
Albertus Joni* \\ Philosophy graduate doctorate at Marquette University, \\ Milwaukee United States America (USA) \\ Email: logos2014.sinaksak@gmail.com
}

\begin{abstract}
Abstrak
This paper will elaborate the different Platonic elements of dialogue as philosophical basis for Gadamerian hermeneutical structures. The intersubjective cross-examination found in Plato's Dialogue shows that the real meaning comes from the real encounters between speakers; or in Gadamer's term: encounters between text and the reader. For Gadamer, it is always important in this pursuit of meaning and truth that we examine our own prejudice. Cross-examining our own claim of truth and belief is an essential element in Gadamer's hermeneutics. I argue that we can see how the Platonic model of dialogue is easily aligned with the Gadamerian positive approach towards 'traditions.' There is a constant dialogue at work in interpretation, a dialogue between the past and the present, between different traditions and points of view. Dialogue is an important keyword for both Plato and Gadamer in their efforts to their existential quest of wisdom.
\end{abstract}

Keywords: platonic dialogue, hermeneutics, Gadamerian approach, dialectic, meaning.

\section{Introduction}

This paper tries to assess the possible interweavement between the Platonic dialogues and Gadamerian hermeneutics. I will start by (I) describing the dialectical process and its relationship with the dialogues in Platonic works. I believe that this basic description will help us to comprehend better the Platonic concept of hermeneutics. (II) I will also explain the reasons why the Platonic model of cross-examination approach might justify the concept of prejudice and the positivity of tradition in Gadamerian hermeneutics. I will finally follow by (III) examining whether dialectic in Platonic dialogues and Gadamerian hermeneutics is a methodological approach more than an 'unstructured'

\footnotetext{
${ }^{*}$ Albertus Joni, is a philosophy graduate doctorate at Marquette University, Milwaukee United States America (USA)
} 
ontological approach to the real experience. I assume that Gadamer's appreciation of the tradition and prejudice in his theory of hermeneutics comes from his understanding of the latter part. I also believe that since the Platonic model of dialogue differs from the rhetoric model, the purpose of dialectic opens a new possibility for an existentialist pursuit of truth - which is also emphasized by Gadamer.

\section{Characters of Platonic Dialectic and Dialogues}

What is the meaning of dialectic in Platonic dialogues? I think Plato himself would be bewildered by this question as he never gives us a definitive answer. Dialectic is defined rather merely in the Dictionary of Merriam-Webster as (a) "discussion and reasoning by dialogue as a method of intellectual investigation," and (b) "the Platonic investigation of the eternal ideas." Oxford English Dictionary defines dialectic as "the art of investigating or discussing the truth of opinions." We can sense the teleological element in these definitions of 'dialectic'; the words 'investigation' and 'discussion' - which are exercised in the dialogues - seem to point to the purpose of the dialogue itself, which is the truth. How did Plato lead his interlocutors to understand the truth in that dialogic investigation? Liu and Sui $(2014,755)$ try to answer this question by linking Platonic dialogues with Gadamerian model of dialogue that emphasizes the openness, equality, and sincerity. These are the main characteristics of the Platonic dialogue and what Socrates wants is the full engagement of the participants in the discovery and inquiry of truth and reality.

The Sophist is driven more by the desire to distinguish himself and is not genuinely committed to rationality. Unlike the discussions with the Sophists where the participants appeared to be intimidated, dialogues with Socrates were always under an atmosphere of openness, equality, and sincerity (Liu and Sui 2014, 756). For example, when talking about what justice is in The Republic, Cephalus, Polemarchus, Thrasymachus, Glaucon, and Adeimantus give their opinions one after another. Socrates gives his opinions and refutations one by one. Although not every participant is so polite, Socrates is quite competent in putting 
the overall situation under control and makes sure that it is open, equal and sincere. One participant who is also a sophist, Thrasymachus, seems to be so confident in his arguments that he "would be ironical and unwilling to answer" and seems to "give a loud, sarcastic laugh" to his dialogue partner (The Republic 336e-337a). However, Socrates always tries to answer him politely "if Polemarchus and I made an error in our investigation, you should know that we did so unwillingly" and "(T)hat's because you are a clever fellow Thrasymachus" (Republic, 337a). A good atmosphere is a premise for the successful proceeding of dialogue. Although it is not the main topic under concern, it gives the participants the feeling of openness, equality, and sincerity. No matter what the reaction of other participants towards his thoughts, Socrates seems to be so charismatic that he can always bring them to such an open atmosphere which can encourage them to air their views.

Gjesdal (2010, 67-70) - a famous Gadamerian scholar - proposes that the Platonic dialogue is an "ongoing process of coming to an understanding about a given subject matter, is defined by its being (a) bilateral, (b) oriented toward a subject matter, and (c) nonconclusive." These three characters of the Platonic dialogues imply that knowledge requires that the interlocutors understand the rationality of the other's standpoint. When a speaker leaves behind an original claim for a result of his/her thoughtful deliberation, he or she is only getting closer to knowledge as accurate, justified belief (Gjesdal, 68). Platonic dialogues seem to have been staged as interactions where the listeners and speakers become immersed in the scene (Fortunoff 1998). For Gadamer, as for Plato, dialectic is inseparable from the dialogue. Bathold (2019) points to four main factors of dialogue in Gadamer's philosophical hermeneutics:

"(1) a dialogue is focused on die Sache, the subject matter. The aim of the dialogue is not to win the other over to one's side-it is not a debate. Nor does it aim at a subjective understanding of the other. Rather, both parties open themselves to agreeing on the matter itself.

(2) Dialogue requires that each party possesses a "good-will" to understand, that is, an openness to 
hear something new in such a way as to forge a connection with another. Thus one could say that dialogic openness aims at solidarity.

(3) A good dialogue entails a willingness to offer reasons and justifications for one's views. One must be open not only to the voice of the other but to make an effort to explain oneself to another.

(4) a good dialogue requires a commitment that one "knows one does not know."

The general-purpose Platonic dialogues are the change of Athenian moral order, which demands a discussion instead of an ending statement. What is on Socrates' mind is how to improve the interlocutors' understanding of major moral issues rather than tell them what they should do. He is fully aware that doctrines and conclusions have little effect on people's souls. Their dogmatic opinions or traditional ideas must be changed little by little and only by the careful examination of each bit of their thought can they change what has long been held, drawing insights from the dialogue.

The rigorous cross-examination is the process. In discussing what justice is, Socrates listens carefully to his interlocutors' opinions, analyzes with them and tells what is wrong with their opinion. However, he does not give his definition of what is justice. It is the process towards the truth that counts most since the process of dialogue also reflects the process of thinking; thus, dialogue with Socrates become a good practice of thinking - another goal of Platonic dialogue. Therefore, people can see that Platonic dialogue emphasizes the process instead of the conclusion. The Platonic dialogue aims for knowledge which is realized through dialogic cross-examinations instead of monologic teaching. In the next part, I will focus on this Platonic cross-examination process and relate this idea with the Gadamerian concept of truth and prejudice. 


\section{Gadamer's Prejudice and the Cross-examinations in Platonic Dialogues}

I argue that Gadamer harnesses these characteristics of the Platonic dialogic element in his understanding of objectivity, of the truth. Over and against the 'objective-scientific' conceptions of truth, Gadamer asserts that truth is primarily an event, a phenomenon, at which someone encounters a more extensive thing and beyond himself. The truth is not the consequence of applying some pair of criteria that demand the distanced judgment of adequacy or inadequacy of the subject. For Gadamer, "truth exceeds the criteria-based judgment of the individual (Bathold 2019)." From the perspective of hermeneutics, the main characteristic of the Platonic dialogues is their 'eventfulness.' Generally, the Platonic dialogue shares the general characteristics of dialogue in hermeneutic understanding. Platonic dialogue is proceeding under an atmosphere of openness, equality, and sincerity as I have mentioned above. It highlights the process rather than the conclusion. What one gets, at last, is better self-understanding and self-improvement. Some ideas from the mind of the interlocutors are not as evident as when they are spoken out. In exchanging their thoughts, some interlocutors and Socrates can have a better understanding and whether they can persuade themselves. Thus, either by attempting to get their thoughts clear or trying to understand the others, Platonic dialogue is helpful to the participants to achieve self-understanding and self-improvement.

This self-understanding and self-improvement come as results of examining our own truth, the subjective truth, in the process of dialogue. Cross-examining our own claim of truth and belief is an essential element in Gadamer's hermeneutics. Gadamer also speaks about the Heideggerian disclosure of the fore-structure of understanding in the hermeneutic experience. The fore-structure, according to Heidegger, is a distinctive capacity that occurs in all individuals to perceive the meaning of being (Holroyd 2007, 3). What the fore-structure offers is an indistinct comprehension of the existential nature of existence. What is implied is that every meeting we have is grounded and directed by something preexisted - a way of conceiving that has been decided even before we are interested in that meeting. Gadamer believes that within the fore-structure 
of understanding, whenever we recognize and comprehend something, the interpretation is founded mainly upon what Heidegger frames as our fore-having, fore-sight and fore-conception. What all of this guide us to understand is that there can never be a presupposition-less stance in any act of interpretation (Holroyd 2007, 3). Awareness that we possess a fore-structure of understanding is often taken for granted as prejudice and tradition which should be removed in the pursuit of the objective truth. Gadamer does not agree with this negative view of tradition and prejudice. Gadamerian hermeneutical process emphasizes the role of this tradition and prejudice. Gadamer writes:

"Even a master of the historical method is not able to keep himself entirely free from the prejudices of his time, his social environment, and his national situation, etc. Is this a failing? And even if it were, I regard it as a necessary philosophical task to consider why this failure always occurs wherever anything is achieved. In other words, I consider the only scientific thing is to recognize what is, instead of starting from what ought to be or could be (Gadamer 2004, 512).”

Cross-examination is the pattern in the Platonic dialogues, containing the uncertainty and ambiguity of meaning in the conversation of the participants, resembles the Gadamerian appreciation of the tradition and prejudice. In the closely and eagerly questioned arguments, cross-examination in the Platonic dialogue takes shape. It forces respondents to think deeply and try to realize their fore-structures of thinking: tradition and prejudice. It forces respondents to think profoundly and attempt to remove any ambiguity. Sometimes people do not doubt or take their' common sense' for granted. Nothing is so certain by doing the cross-examination, and no concept is so absolute that there is no doubt about it. It can help the participants in the dialogue - both the respondents and the questioners - to cultivate a spirit of the query (Liu \& Sui 2014, 760). The inquiry is an invitation to dialogue, which in turn mandates openness and curiosity. In this way, he departs from earlier 
hermeneutic endeavors that attempted to devise a methodology for proper interpretation of meaning (Weinsheimer 2004, 161). How would Plato deliver his cross-examinations? Kinney $(1983,243)$ proposes four stages of development of the Platonic dialectic that is demonstrated in Plato's text.

On the first level of the dialogue, Plato formulates the dialectical process as a five-fold scheme of name; description; image; knowledge or understanding of the object; and the true reality. While this scheme is not a definition of dialectic, it is the dialectical attempt to give a rational account or explanation of knowledge by listing its components and describing their interaction (Kinney 1983, 243). The order of the scheme itself marks the ascent to full knowledge, the experience of the Eidos themselves, through logos. First, words are questioned in order to understand their meanings or definitions better. Second, the description itself is worked out by turning to definitions. Third, there is the examination of particular instances, whether in the form of objects or representations of an object. Fourth, one turns to the minds' activity, the source of understanding and correct opinion where the mind directs its inner vision to the essences, the actual realities. Rational thought is an ongoing interplay between the first four components (Kinney 1983, 243).

Cross-examination is a kind of technique that can always be used by interlocutors in their daily lives. Not only is the topic being challenged, but other ideas that are so familiar and "right" may also be suspected. Cross-examination is such an effective way that it corresponds well to the Platonic philosophy as a never-ending pursuit of truth. Crossexamination, in short, is a kind of refusal of the notion of a fixed meaning. As well as Plato, Gadamer believes the meaning of a text (or words spoken in dialogue) is never purely a function of the original intention of the author/speaker, but somewhat equally dependent on the actual situation of the reader/listener. He decenters the author or speaker by maintaining that understanding is not about reproducing the predefined, intended meaning in as accurate form as possible, but rather producing meaning through the interplay of dialogue between the author/reader and speaker/listener (Gadamer 2004, 288). 
In the Republic, Socrates asks one question after another until his interlocutors have nothing to say and have to turn to Socrates to make things clear or give up their previous ideas. Socrates applies irony as a constant dialectic device to the guidance of the participant's understanding of knowledge. The irony is a dialectic device used by Socrates in The Republic, which means that different ideas are not refuted at first, but affirmed, however, with the discussion going on, the interlocutors will notice the absurdness of their previous thought that they have to doubt it and negate it. Socrates is quite modest, and he always appears as an ignorant person. He will praise the sophists for their "extensive information and learning." He encourages them to give their "wise opinion" concerning a topic, and he will somewhat agree with them. Later, by discussion, the "wise people" will find the irrationality in their argument. Maybe at first, Socrates knows something wrong in the argument of his interlocutors, but he does not deny their ideas directly or instantly but give them positive responses. The initial agreement helps to create a friendly atmosphere in the first place and also shows sincerity because it indicates that participants of dialogue are on the same boat and they want to go ahead together. The dialogue participants can dig deeper into the topic without much enmity or aversion in the first place. After all, the primary purpose of the dialogue or Socrates inquiry is to provoke people's interest and attention to think deeply about the condition and purpose of their life and their souls. This model of provocation challenges the interlocutors to examine their prejudices and tradition and at the same time encourages them to create new meaning in the dialogue with Socrates' horizons.

\section{Is Dialectic a Systematic Method or More an Experience?}

We have seen that both Plato and Gadamer have expressed their ways of doing the cross-examination in the dialogue. We know that this element of dialectic is considered as one crucial aspect in the dialogic process. I was wondering whether there exists such a 'method' in both Platonic and Gadamerian dialectics or they are more 'free' inquiries of truth based on experience. 
I will begin by saying that Gadamerian hermeneutics is not mainly a methodology, nor is it a procedure of reading or translating the 'correct' meaning of the text or spoken word. Neither can it be a procedure to prevent misunderstanding of the speaker's purpose since Gadamer believes there is not any fixed reality from the meaning of these words. The spoken words instead display new hints of meaning in each new dialectical investigation. So, Gadamerian hermeneutics does not seek to replicate the text or speech to purely capture what someone has said in order to find the meaning, but rather, seeks to investigate opportunities for the creation of new meaning which is generated in dialogues between the readers or speakers. The goal of this exploration and cross-examination between the listeners and speakers, for both Gadamer and Plato, is to reach an understanding that centers less on asserting one's point of view and more on personal transformation.

Consequently, meaning (what the words mean in that context) can never be separated from application and experience. The thought of an effect is critical in another way. Not only is that the listener a consequence of the speaker, because the horizons of both speaker and speaker fuse; the listener can also be part of the new exploration of meanings the dialogue. Every encounter with tradition that takes place within the historical-consciousness involves the experience of tension between the speaker and 'the present.' 'Historically effected consciousness' or what simply Gadamer refers to 'effective history' claims that "understanding is, essentially, a historically effected event (Gadamer 2004, 300)." This is a challenging thought to grasp. In the areas of literary criticism and hermeneutics (when hermeneutics principally referred to the methods and rules of interpretation), it was initially assumed that meaning dwelt with the main speaker or author. Thus, the objective of interpretation was to discern the author's or main speaker's intention that would unlock the objective meaning for all times. But Gadamer thinks that it makes no sense to talk about the meaning of a text or speech aside from our listening or reading-experience of it (Weinsheimer 2004, 159). Thus dialogue, whether using text or speech among interlocutors, always has something different to say since meaning is generated through the occasion of disclosure instead of 
something created by a speaker or text (Weinsheimer 2004, 160). Although Gadamer is concerned about recognizing the affected consciousness of the text or speaker, his previous work does not define an immediate inclusion of "a critical based reflection, that being the identification, inclusion, and critique of socio-political infrastructures and agendas." (Smith 1991, 24). In his later work, however, Gadamer becomes more explicit in his belief that hermeneutic phenomenology is open to the traditional horizon of the dialogue partners while also being open to a critique of that tradition.

We can compare this Gadamerian approach to fusions of meanings in Plato's background of dialogues. Dialogues can be further contrasted to the model of rhetoric. Rhetoric in the ancient Greek was the traditional art or technique to debate. It became a unique knowledge, and some people taught rhetoric as the technique was needed in public speaking. They taught people how to use language and how to argue in order to win the agreement from the polis. In the original sense, rhetoric means the art to argue, and the primary purpose is to defeat the opponent and to win out. The sophist dialectic follows this model; it is more persuasion than an inquiry and a discovery of truth. Socrates dislikes the method of argument for win's sake. There is no fusion of horizons - no new meaning coming out from the Sophist dialectics since the speaker forces his ideas to the listener in intention to rule out arguments and to win. It is a different approach with Plato's dialogue. Plato concentrates more on the collaboration and reasoning process with the interlocutors for the inquiry and discovery of truth (Kidder 1997, 55).

In this sense, the Socratic dialectic is more like a dialogue, the way of the discussion by the question-answer process. The discussion with Socrates may be floundering and struggling in the interlocutors' mind and soul, but they get closer to truth and reality. They are making progress towards knowledge as fusions of horizons. While understanding the previous claim (and prejudice), Socrates' interlocutors participate in the life of the tradition which never ceases to affect their existence even as it receives continuous feedback from their interpretive efforts. This is what Gadamer calls 'effective historical consciousness,' a consciousness that remains within the circle of understanding peculiar to the age yet 
subtly updates it in light of experience and feedback from this experience. Gadamer writes:

"Tradition is not simply a precondition into which we come, but we produce it ourselves, since we understand, participate in the evolution of tradition and hence further determine ourselves. Thus, the circle of understanding is not a 'methodological' circle, but describes an ontological structural element in understanding (Gadamer 2004, 281).”

I think Gadamer is right when he says that we cannot remove all of our prejudices in this dialogic process. Gadamer's analysis of aesthetic and historical consciousness shows what difficulties these attempts imply. In Truth and Method (Gadamer 2004), the process of approaching different horizons is entitled 'fusion of horizons.' By the fusion of horizons, we encounter the 'Different,' enabling it to speak freely.

By engaging in interpretive acts from within the tradition, the interpreter engages in its historical being, borrows from the inventory of meaning, and upgrades its respected prejudices. In turns, he/she constitutes a new historical perspective in his/her world. In the dialogues with his interlocutors, for example, Socrates would ruin some common sense or proposal that was held by individuals as criteria in ethics and life. The Socratic dialectic makes people recognize what they thought was not so dependable and even contradictory and ridiculous. Thus, our prejudices are not untouchable; they are free to change. Rational analysis lets interpreters sort out what is tenable and what is not in our tradition: "True prejudices must still finally be justified by rational knowledge (Gadamer 2004, 242).”

The prejudicial character of understanding also means that, whenever we understand, we are involved in a dialogue that encompasses both our own self-understanding and our understanding of the matter at issue. In the dialogue of understanding our prejudices come to the front since they play a crucial role in opening up what is to be understood, and since they become evident in that process. As our prejudices thereby become apparent to us, so they can also become the focus of questioning 
in their own turn (Malpas 2013). Immersing ourselves in an unfamiliar tradition gives us a chance to reflect seriously on our pre-understandings, together with the historical distance itself which in turns would stimulate self-reflection and self-criticism. The Platonic dialectic in the dialogue represents Socrates' understanding of the process of attaining knowledge through this kind of self-criticism.

The Platonic dialectic is more like the question-answer process of dialogue based on their ordinary backgrounds and prejudices than a sophisticated philosophical method of attaining truth or of rhetoric. Unlike the sophist dialectic whose aim is to win an argument without paying attention to reality and truth, the Socratic dialectic is to focus on the more reasonable and the more real. It leads individuals away from view and to understanding by analyzing their given prejudices on that opinion. Plato would not inform his interlocutors the answers to those big questions, but encourage them to dig the answers with him. Plato's dialectic triggers new thoughts and new ideas. After the negation of the interlocutors' previous ideas, he will lead them to new ones. However, Socrates does not give any certain conclusion to a topic. He 'only' acts as a guide or a midwife. The production of an idea and meaning is due to every individual himself.

Plato, seems to me, does not consider dialectic as a method, because for him correct understanding is the understanding that leads to the ontological level rather than methodological. This means that truth can be achieved not through methods but through real dialogues, where more questions can be asked. I propose that his dialectic serves more as a practical philosophy. In this framework, I can see Plato's connection to the Gadamerian hermeneutics which presents the concept of historical and dialectical "experience," where knowledge is not a mere bias of perception but is an event and an encounter. Both Gadamer and Plato emphasize that meaning is not produced by individual interiority but from interrelated historical insights that the individual experiences. While Plato teaches that meaning and truth comes not only from himself and his wisdom as a philosopher, Gadamer maintains that meaning also comes from the historical dimension of the life of the interlocutors. 
The philosophy of Gadamer hermeneutics requires that our form rests on hermeneutical principles, and hermeneutics rests on human existential principles. He rejects all forms of certainty and continues Heidegger's existentialism with a point of suppressing the dialectical logic among the speakers or the readers. Dialectics must be understood existentially because the essence of understanding the conversation or the text is our understanding of ourselves and our own being. When we participate in the dialogues, at present, we also present our life experiences in the past, thus giving birth to a balance of understanding of ourselves.

In this existential context, Plato also relates human understanding to an interpretive action. The process of understanding the interlocutors is always preceded by the pre-understanding of the participants of the dialogues. We approach the dialogues always with a set of questions or with potential meaning in the conversations. It is through this expectation horizon that we enter a process of understanding that is conditioned by the historical reality. Plato provides a dialectical approach for the reader both by the subject matter discussed in the dialogues, the first level, and the structure of the interchange between the dialogic partners, the second level. Using the Gadamerian approach, even I, the reader, can bring the dialectical training to the third level when I reflect on the first and second levels and come to a clear understanding of dialectic. By taking me through his dialogues, Plato, in effect, teaches me how to think more clearly and to reason correctly. Dialectic is the critical link between thought and reality. These existential elements in the dialectical understanding of Gadamer and Plato go beyond the systematic method of analysis, and therefore, I believe that dialectics is neither a systematic method nor a logical scheme. It is more an existentialist approach to pursuit truth in concrete human life.

\section{Conclusion}

From what Plato says in some of his texts, but also from the openness and ambiguity of his own thinking, as reflected in many of his writings, it seems evident that the dialogic structure is not only an external quality of his dialectic. In the concrete form of crossexamination, the dialectic is shown as a unique form of doing philosophy, of seeking the truth. We have seen that doing philosophy and doing it by means of dialogues are the same thing for Plato. Contrasted with the 
sophist dialectic, which is more persuasion than an inquiry and a discovery of truth, Plato chooses a different approach: open, equal and sincere dialogues with his interlocutors.

Gadamer, who regularly relates to Plato in his writings about hermeneutics and his conception of hermeneutics, could be understood in many ways as someone who tries to explain further the Platonic dialogic reasoning and thinking. Both his explicit references and his theory of hermeneutics may show Plato's influence on Gadamer's work. Moreover, on the other side, Gadamer's ideas offer the fruitful tools for translating the structure and the extent of Plato's dialogues in contemporary thoughts.

The interweavement of thoughts between Plato and Gadamer can also be seen in their efforts to give positive meaning to prejudice and tradition. There is a constant dialogue at work in interpretation, a dialogue between the past and the present, between different traditions and points of view. The past does not have to be the distant past of antiquity - it can be the recent past of a moment just gone; the point is that in both cases the same hermeneutical problem arises: how can the different interlocutors accommodate or negotiate meanings external to themselves? Platonic dialectic seems to affirm the Gadamerian hermeneutical approach that meaning itself is always produced by the coming together of the immediate and the point of tradition one seeks to understand.

Good dialogue requires a humble playfulness in which we get caught up and lose ourselves in connection with another (Weinsheimer 2004, 161-162). The dialogue indicates the central motif of Gadamer's notion of truth: "To reach an understanding in a dialogue is not merely a matter of putting oneself forward and successfully asserting one's own point of view, but being transformed into a communion in which we do not remain what we were (Gadamer 2004, 379)." When we participate in the dialogues, at that time, we then present our life experiences in the past, thus giving birth to a balance of understanding of ourselves. These existential elements in the dialectical understanding of Gadamer and Plato go beyond the systematic method of analysis. It is instead an existential pursuit of wisdom; a philosphia.

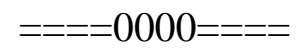




\section{DAFTAR PUSTAKA}

Gadamer, Hans-Georg. Weinsheimer, Joel and Marshall, Donald G. (trans.). Truth and Method. London: Bloomsbury Academic. 2004.

Gadamer, Hans-Georg and Silverman, Hugh J. (eds.). Gadamer and Hermeneutics. New York: Routledge. 1991.

Gjesdal, Kristin. "Davidson and Gadamer on Plato's Dialectical Ethics" in Machamer, Peter and Wolters, Gereon (eds.) in Interpretation: Ways of Thinking about the Sciences and the Arts. Pittsburgh: University of Pittsburgh Press. 2010.

Holroyd, Ann. E. MacManus. “"Interpretive Hermeneutic Phenomenology: Clarifying Understanding" in Indo-Pacific Journal of Phenomenology, Vol.7, 2007. Pp. 1-12.

Kinney, Ann M. "The Meaning of Dialectic in Plato" in Asulegung, Vol. 10, 1983. Pp. 229-246.

Liu, Chunge and Sui, Xiaodi. "Understanding the Platonic Dialogue from the Perspective of Gadamer's Hermeneutics" in Theory and Practice in Language Studies. Vol 4, April 2014. Pp. 758-765.

Smith, C. "Plato as Impulse and Obstacle in Gadamer's Development of Hermeneutical Theory" in H.J. Silverman (Ed.). Gadamer and Hermeneutic. New York: Routledge. 1991. Pp. 23-41.

Weinsheimer, Joel. "Meaningless Hermeneutics?" in Kajewski, Bruce (ed.). Gadamer's Reppercussion, California: University of California Press. 2004.

Bathold, Lauren Swayne. "Hans-Georg Gadamer" in Internet Encyclopedia of Philosophy. https://www.iep.utm.edu/gadamer. Accessed April 9, 2019. 
"Dialectic" in Merriam-Webster Dictionary, https://www.merriam-webster.com/dictionary/dialectic. Accessed April 4, 2019.

"Dialectic" in Oxford English Dictionary, https://en.oxforddictionaries.com/definition/dialectic. Accessed April 4, 2019.

Fortunoff, David. “Dialogue, Dialectic, and Maieutic: Plato's Dialogue As Educational Models" in Ancient Philosophy, Boston: Twentieth World Congress of Philosophy. 1998. https://www.bu.edu/wcp/Papers/Anci/AnciFort.htm. Accessed April 12, 2019.

Malpas, Jeff. "Hans-Georg Gadamer" in The Stanford Encyclopedia of Philosophy (Summer 2013 Edition), Edward N. Zalta (ed.) https://plato.stanford.edu/entries/gadamer. Accessed April 9, 2019. 